\title{
Evaluation of hop (Humulus lupulus) as a repellent for the management of Drosophila suzukii
}

\author{
Thomas Reher ${ }^{\mathrm{a}}$, Vincent Van Kerckvoorde ${ }^{\mathrm{b}}$, Loes Verheyden ${ }^{\mathrm{a}}$, Tom Wenseleers ${ }^{\mathrm{c}}$, Tim Beliën ${ }^{\mathrm{b}}$, \\ Dany Bylemans ${ }^{\mathrm{b}, \mathrm{d}}$, Johan A. Martens ${ }^{\mathrm{a}, *}$ \\ ${ }^{a}$ Center for Surface Chemistry and Catalysis, Department of Microbial and Molecular Systems, KU Leuven, Leuven, Belgium \\ ${ }^{\mathrm{b}}$ Department of Zoology, pcfruit vzw, Sint-Truiden, Belgium \\ ${ }^{\mathrm{c}}$ Laboratory of Socioecology and Social Evolution, Department of Biology, KU Leuven, Leuven, Belgium \\ ${ }^{\mathrm{d}}$ Department of Biosystems, KU Leuven, Leuven, Belgium
}

\section{A R T I C L E I N F O}

\section{Keywords:}

Spotted-wing drosophila

Asian fruit fly

IPM

Behavioral control

Headspace analysis

SPME GC-MS

Field experiment

\begin{abstract}
A B S T R A C T
Over the past decade, the spotted-wing drosophila, Drosophila suzukii Matsumara has become one of the most important pests of soft- and stone fruits throughout Europe. Currently, the majority of growers still rely heavily on a limited portfolio of chemical foliar spray insecticides. Alternative strategies such as attract and kill (pull) or behavioral control systems that repel or deter $D$. suzukii from damaging fruits (push) are less common. We evaluated the potential of hop (Humulus lupulus L.), as a repellent for the Integrated Pest Management of D. suzukii, in controlled greenhouse conditions as well as at commercial field sites. In greenhouse cage tests on fruit or attractant medium, the positive controls thymol and 1-octen-3-ol as well as certain hops significantly reduced larval infestation levels compared to an untreated control, while other hop products showed only numerical reduction in infestation. A controlled field trial on raspberries (Rubus idaeus L.) failed to replicate these results, both for the positive control repellents as for the hop samples. In field experiments in commercial raspberry and blackberry (Rubus fruticosus L.) plantations, no significant reduction in oviposition or differences in population density could be observed for the hop treated plots as compared to the untreated. Through SPME headspace analysis of the hops, a number of compounds were associated with the efficacy observed in the greenhouse, even though different hop varieties were found to have notably different volatile profiles.
\end{abstract}

\section{Introduction}

Since its first observation in Europe in 2009, the spotted-wing drosophila (Drosophila suzukii Matsumara), has expanded steadily throughout Southern- and Western Europe (Cini et al., 2012) and has become one of the most important pests of high value fruit crops such as cherries (Prunus avium L.), raspberries (Rubus idaeus L.), and blackberries (Rubus fruticosus L.) (Asplen et al., 2015; Cini et al., 2014). The zero-tolerance policy of the auction houses and retailers means that any infestation with $D$. suzukii leads to the complete rejection of a batch (Asplen et al., 2015, M. Thoelen, BELORTA auctions, Personal Communication, February 24th 2017). The resulting economic pressure has pushed growers to adopt calendar spray programs with broad-spectrum insecticides in their attempts to remain competitive (Asplen et al., 2015; Haye et al., 2016). Increased use of insecticides can harm beneficial organisms (disrupting natural pest control), lead to higher pesticide residues on fruit (Hamilton et al., 2004) and ultimately hamper the long-term efficacy of insecticides by the development of genetic resistance (Smirle et al., 2017). Furthermore, the increased wariness of consumers towards pesticide use (Nur et al., 2011) has led to increasingly strict pesticide regulations. As a consequence, the development of low impact, alternative control methods is highly desirable.

Bio-based substances for the treatment of $D$. suzukii have been found in a wide range of plants, including oils from Myrtaceae (Jang et al., 2016; Park et al., 2017), Lamiaceae (Park et al., 2016) and various other plant species (Erland et al., 2015; Kim et al., 2016). Both direct contact toxicity as well as toxic effects from volatile compounds have been demonstrated on $D$. suzukii. Monitoring, mass trapping and attract and kill approaches are common tools in the management of $D$. suzukii and in general, they do not require physical contact between treatment and crop. The same advantage holds for repellent based strategies. Behavioral control is defined as the use of stimuli that either stimulate or

\footnotetext{
* Corresponding author.

E-mail address: johan.martens@kuleuven.be (J.A. Martens).
} 
inhibit a behavior and thereby change its expression (Foster and and Harris, 1997). Both repellent (long range) and/or deterrent (short range) effects can be employed in a plant protection strategy. Examples of repellent use in crop protection are less common than attractants, but have recently started to attract more interest (Deletre et al., 2016; Isman, 2006; Jones et al., 1996).

Knaden et al. (2012) identified 6 aversive substances to D. melanogaster. 1-Octen-3-ol and geosmin have been confirmed as possible oviposition deterrents for $D$. suzukii, both in controlled- and field environments (Wallingford et al., 2017, 2016, 2015). These substances have a typical earthy (Gerber and lechevalier, 1967), decaying, or fungal smell (Rapior et al., 1997), and are thought to be perceived as warnings for sites that are unsuitable for oviposition (Stensmyr et al., 2012; Wallingford et al., 2016). Recently, several researchers have focused on various essential oils as repellent for $D$. suzukii, of which thymol proved to be one of the most effective, both under laboratory conditions (Renkema et al., 2016) as well as under field conditions (Renkema et al., 2017).

H. lupulus is both a bittering agent and essential aroma source used extensively in brewing. It produces a myriad of compounds that accumulate mainly in its female inflorescence (hop cones), including alphaand beta-acids, flavonoids such as xanthohumulol and various terpenoid essential oils, of which myrcene, humulene and caryophyllene are the key ones (De Keukeleire et al., 2003; Verzele, 1986). Compared to hop cone extracts, $H$. lupulus leaves contain a much smaller concentration of volatile compounds (0,05\% vs. $2 \%$ ) (Katsiotis et al., 1990). A large number of hop cultivars exist, each with its own aromatic profile, ranging from fruity or herbal to musty or earthy (Eyres et al., 2007; Meilgaard et al., 1982; Nance and Setzer, 2011). Spent hops from brewing have been shown to have a repellent effect on storage beetles (Bedini et al., 2015; DeGrandi-Hoffman et al., 2012) while Jones et al. (2003, 1996) have shown a repellent effect of hop extracts on the two-spotted spider mite (Tetranychus urticae Koch). Solvent or distillation extracts from hops, have also been evaluated as an insecticide for storage pests (Aydin et al., 2017) and mosquitoes (Bedini et al., 2016).

Based on the earlier studies of plant essential oils for the treatment of D. suzukii, and the suggestion that hop and hop essential oils act as potent insect repellents, we evaluated the repellent effect of hop pellets on D. suzukii in soft fruits, and identified possible target molecules associated with efficacy.

\section{Materials and methods}

\subsection{Tested products}

All hop samples tested were commercially available for food production. HOP00 (Herbovan, K12300, wild harvest, 2014 harvest) was procured from a local health store as unrefrigerated hop cones. HOP01 (var."Fuggles", 2014 harvest, 3\% Alpha acid (AA)), HOP02 (var. "Halertau Hersbrucker", 2016 harvest, 3.7\% AA), HOP03 (var. "Halertau hersbrucker", 2015 harvest, 2.9\% AA), HOP04 (var "Amarillo", 2015 harvest, 8.7\% AA), HOP05 (var "Goldings", 2015 harvest, 5.1\% AA), HOP06 (var "Magnum", 2016 harvest, 14.3\% AA) and HOP07 (var "CTZ", 2015 harvest, 17.2\% AA) were bought at Brouwland (Beverlo, Belgium) as refrigerated vacuum packed hop cone pellets. The large volume supply of HOPOF (var "Magnum", 2016 harvest, 14.12\% AA) for field testing was obtained directly from a hop grower (Eurohop Lagache, Poperinge, Belgium) as unrefrigerated modified atmosphere packaged hop cone pellets. Thymol and 1-octen-3-ol were purchased at Sigma Aldrich and impregnated onto porous calcium silicates $(6,8 \% \mathrm{v} / \mathrm{w})$ in an autoclave for $1 \mathrm{~h}$ at $150{ }^{\circ} \mathrm{C}$ and $70^{\circ} \mathrm{C}$ respectively.

\subsection{Greenhouse test}

To evaluate short range efficacy of hops in repelling $D$. suzukii, a greenhouse cage experiment was conducted. Flies were reared in a climate chamber at $24^{\circ} \mathrm{C}, 60 \%$ relative humidity (RH), 16/8 day/night on an artificial diet containing $90 \mathrm{~g}$ of fine cornmeal, $55 \mathrm{~g}$ of white sugar, $42 \mathrm{~g}$ of fresh baker's yeast (Saccharomyces cerevisiae Meyen), $3 \mathrm{~g}$ of agaragar and $2 \mathrm{~g}$ of Methylparaben per liter medium. The colony was initiated in 2016 and periodically refreshed with wild type $D$. suzukii caught in the untreated plots of a cherry or blackberry orchard located at pcfruit npo, Sint-Truiden, Belgium.

A first set of choice tests was performed with fully vine ripened grapes (Vitis vinifera L. cv. Prior sourced from untreated plots at pcfruit npo, free from insecticide residue. Grapes were removed from their stems and individually inspected for absence of prior oviposition using a dissecting scope and subsequently pierced multiple times with a lancet to increase attraction and facilitate infestation. Four uncovered $135 \mathrm{~mm}$ petri dishes were placed $40 \mathrm{~cm}$ apart in an insect cage (BugDorm BD6610). In each petri dish, a single grape was placed on top of a moist $125 \mathrm{~mm}$ filter paper treated with the test products. Two randomly selected positions were left untreated to serve as a control, one filter paper was infused with $100 \mu \mathrm{l}$ of the positive reference repellent Thymol and one was dusted with $120 \mathrm{mg}$ of pulverized HOP0O hop cones. This rate equates to approx. $98 \mathrm{~kg} / \mathrm{ha}$, a practical maximum in a commercial setting. Hop cones were pulverized using a knife mill (Retch Grindomix GM 200) and stored in airtight vials for a maximum of three days. Flies (20 $q$ en 5 of mixed age) were left in the bugdorm cage to mate and oviposit for $24 \mathrm{~h}$ under greenhouse conditions $\left(20{ }^{\circ} \mathrm{C}+-2{ }^{\circ} \mathrm{C}, 60 \%\right.$ $+-20 \% \mathrm{RH}, 12 / 12$ day/night), after which they were removed. The number of larvae present in the grapes was then assessed using a dissecting scope (Carl Zeiss Gmbh, Stemi 2000).

A second set of choice tests was set up, substituting the grapes with an attractant medium. The attractant medium was optimized for maximal attractiveness and reproducibility at times when no fresh fruits are available. The attractant medium followed the recipe of the rearing nutrient medium, but water was substituted by strawberry juice extracted from residue-free fruits, collected from untreated plants cultivated on site. Drosophila vials (Greiner bio-one, 217101) containing $15 \mathrm{~mL}$ of the attractant medium were placed $40 \mathrm{~cm}$ apart in the insect cage, two were left untreated, one was sprayed with the positive control octenol $(100 \mu \mathrm{l} \geq 98 \% 1$-octen-3-ol at $50 \% \mathrm{v} / \mathrm{v}$ in paraffin oil) and one was dusted with $120 \mathrm{mg}$ of freshly pulverized hop pellets of cultivars HOP01 through HOP07. All tests were replicated four times, randomizing sample positions between replicates.

\subsection{Field efficacy trials}

\subsubsection{Site selection and layout}

Large, homogenous plots in the same growth stage, with sufficient separation and buffer zones between treatments are essential for reliable behavioral study. Trial locations at commercial farms were selected based on overall pest pressure in the previous years and site-specific monitoring of pest pressure level leading up to the trials. Trial layout (Table 1) was optimized for uniform blocks with homogenous infestation levels and clear buffer zones between treatments. Four trial fields were selected, spread across three test sites. Location permitting, treatments were laid out in a randomized complete block design (A and C) or randomly assigned to one of two blocks (B). Monitoring of trapped insects leading up to the trials showed no obvious zonal effects. The field efficacy trials were initiated at economic threshold breach ( $>2$ males in 2 or more traps per plot) and ran till the end of harvest.

The first test site (A), 2016 season, was located at the Research Center for Fruit Growing (pcfruit npo) in Sint-Truiden, in an enclosed, unheated and untreated polytunnel containing various primocane cultivars. The second site (B), 2017 season, was located at an organically certified (TUV Nord) commercial farm, covering approximately 6 ha in Huldenberg (Belgium). The grower did not perform any insecticide applications prior to or during the trial and overripe fruit was removed periodically. All Rubus spp. (floricane) were planted in the soil, in an unheated plastic greenhouse without extra lighting. The third site (C), 
Table 1

Trial locations and layout.

\begin{tabular}{|c|c|c|c|c|}
\hline & LOCATION & TRIAL & BLOCK SETUP & $\begin{array}{l}\text { SUBSAMPLES } \\
\text { PER BLOCK }\end{array}$ \\
\hline $\mathbf{A}$ & $\begin{array}{l}\text { Sint-Truiden } \\
50^{\circ} 46^{\prime} 26.6^{\prime \prime} \mathrm{N} \\
5^{\circ} 09^{\prime} 38.3^{\prime \prime} \mathrm{E}\end{array}$ & $\begin{array}{l}\text { Raspberry } \\
2016(1)\end{array}$ & $\begin{array}{l}5 \times 4 \text { RCBD } \\
(3 \times 3 \mathrm{~m}) \\
3 \mathrm{~m} \text { buffer }\end{array}$ & $\begin{array}{l}1 \text { fruit sample per } \\
\text { block }\end{array}$ \\
\hline B1 & $\begin{array}{l}\text { Huldenberg } \\
50^{\circ} 45^{\prime} 48.0^{\prime \prime} \mathrm{N} \\
4^{\circ} 38^{\prime} 07.3^{\prime \prime} \mathrm{E}\end{array}$ & $\begin{array}{l}\text { Raspberry } \\
2017 \text { (2) }\end{array}$ & $\begin{array}{l}2 \times 1 \\
(25 \times 50 \mathrm{~m}) \\
6 \mathrm{~m} \text { buffer }\end{array}$ & $\begin{array}{l}2 \text { fruit samples } \\
\text { per block } \\
2 \text { traps per block }\end{array}$ \\
\hline B2 & $\begin{array}{l}\text { Huldenberg } \\
50^{\circ} 45^{\prime} 48.7^{\prime \prime} \mathrm{N} \\
4^{\circ} 38^{\prime} 10.8^{\prime \prime} \mathrm{E}\end{array}$ & $\begin{array}{l}\text { Blackberry } \\
2017 \text { (3) }\end{array}$ & $\begin{array}{l}2 \times 1(8 \times 50 \mathrm{~m}) \\
6 \mathrm{~m} \text { buffer }\end{array}$ & $\begin{array}{l}2 \text { fruit samples } \\
\text { per block } \\
2 \text { traps per block }\end{array}$ \\
\hline C & $\begin{array}{l}\text { Borgloon } \\
50^{\circ} 47^{\prime} 55.0^{\prime \prime} \mathrm{N} \\
5^{\circ} 23^{\prime} 36.4^{\prime \prime} \mathrm{E}\end{array}$ & $\begin{array}{l}\text { Blackberry } \\
2017 \text { (4) }\end{array}$ & $\begin{array}{l}2 \times 2 \text { RCBD } \\
(70 \times 80 \mathrm{~m}) \\
12 \mathrm{~m} \text { buffer }\end{array}$ & $\begin{array}{l}2 \text { fruit samples } \\
\text { per block } \\
6 \text { traps per block }\end{array}$ \\
\hline
\end{tabular}

2017 season, was located in Borgloon (Belgium) at one of the largest soft fruit producers of the country $(30+$ ha). Fields were uniformly managed reflecting current IPM standards. All Rubus spp. were planted in drip irrigated pots under vented polythene rain covers.

\subsubsection{Sampling and treatment}

To assess the impact on fruit quality, $100 \mathrm{~g}$ of fruits (free from secondary damage, to rule out secondary infestation) were collected per subsample during the harvesting time following test product application. ${ }^{1}$ Fruit subsamples were taken at random within each plot as described by the EPPO PP1/281 (1) guideline (EPPO, 2013) and larvae were counted on the same day. Larvae were extracted using a $10 \% \mathrm{w} / \mathrm{w}$ $\mathrm{NaCl}$ solution following the protocol of Dreves and Cave, (2014), soaking for $30 \mathrm{~min}$ before evaluation.

Pest population levels were evaluated in all test fields before and during the trials by monitoring traps. Insect traps used at location (B) were based on the "zorro" design (red-black-red banding) (Basoalto et al., 2013). Evian ${ }^{\circledR}$ water bottles $(500 \mathrm{~mL}$ ) were perforated on half of the circumference by $4 \mathrm{~mm}$ holes in the black banded area. For the trial sites (A) and (C), "Drosotrap ${ }^{\circledR}$ NEW" (Biobest, Westerlo, Belgium) traps were used. Traps were secured in the crop at a height of approximately $1.60 \mathrm{~m}$, corresponding to the main fruiting level of the crop.

All traps were baited with a mixture of apple cider vinegar $(75 \mathrm{~mL})$, red wine $(25 \mathrm{~mL})$ and table sugar $(6 \mathrm{~g})$, based on the "Droskidrink" lure composition (Grassi et al., 2014). The attractant mix was replaced by fresh mix after each weekly sampling. The content of the traps was visually inspected on the same day, using white serving trays to serve as a backdrop for counting. Only male flies showing clear wing spots were quantified, as prior testing showed no sex-imbalance in trapping efficiency.

Treatment of trial field (A), was done at the start of the trial by placing 2 open, perforated plastic cups, containing $10 \mathrm{~g}$ of hop or calcium silicate impregnated with thymol or 1-octen-3-ol at 50 and $150 \mathrm{~cm}$ from ground level per plot. Thymol foliar spray was done with a Birchmeyer backpack sprayer with standard nozzle at a $1 \% \mathrm{v} / \mathrm{v}$ concentration until leaf runoff. For the field trials at commercial sites (B) and $(\mathrm{C})$, product application was performed weekly from economic pest threshold breach till the end of harvest. For each row, $100 \mathrm{~kg} / \mathrm{ha}$ of test product was weighed out based on individual row length and distributed manually at the base of the crop across a $1 \mathrm{~m}$ strip. The center path of each row was left untreated.

\subsection{Analysis of hop volatile composition}

To determine the profile of the volatiles released by each of the 9 hop samples used in our experiments, we analyzed two samples of each hop

\footnotetext{
${ }^{1}$ Rubus spp. are harvested on a variable interval depending on ripening speed.
}

variety using headspace solid-phase micro extraction (HS-SPME) GC-MS following a protocol modified from Kovacevic and Kac (2001) and Krofta and Nesvadba (2005). Each sample consisted of $1 \mathrm{~g}$ of ground dry hop placed inside $10 \mathrm{~mL}$ headspace vials, which were then analyzed using HS-SPME GC-MS on a Thermo Trace 1300-ISQ GC-MS equipped with a TriPlus RSH autosampler. The headspace vials were conditioned at $60{ }^{\circ} \mathrm{C}$ in the autosampler oven under constant agitation. After $5 \mathrm{~min}$ of equilibration, the SPME fiber (triphase DVB/Carboxen/PDMS 50/30 $\mu \mathrm{m}$ SPME fiber, Supelco Co., Bellefonte, PA, USA) was exposed to the sample headspace for $30 \mathrm{~min}$. The compounds trapped on the fiber were then thermally desorbed by heating the fiber for $15 \mathrm{~min}$ at $270{ }^{\circ} \mathrm{C}$ in the injection port of the GC. The GC-MS was equipped with a low polarity $30 \mathrm{~m}$ metal capillary MXT-5 column (Restek) with an internal diameter of $0.18 \mathrm{~mm}$ and a film thickness of $0.18 \mu \mathrm{m}$. Splitless injection was used with an inlet temperature of $320^{\circ} \mathrm{C}$, a split flow of $9 \mathrm{ml} / \mathrm{min}$, a purge flow of $5 \mathrm{ml} / \mathrm{min}$ and an open valve time of $3 \mathrm{~min}$. To obtain a pulsed injection, a programmed gas flow was used whereby the helium gas flow was set at $2.7 \mathrm{~mL} / \mathrm{min}$ for $0.1 \mathrm{~min}$, followed by a decrease in flow of $20 \mathrm{ml} / \mathrm{min}$ to the normal $0.9 \mathrm{~mL} / \mathrm{min}$. The temperature was first held at $30^{\circ} \mathrm{C}$ for $3 \mathrm{~min}$ and then allowed to rise to $80^{\circ} \mathrm{C}$ at a rate of $7^{\circ} \mathrm{C} / \mathrm{min}$, followed by a second ramp of $2{ }^{\circ} \mathrm{C} / \mathrm{min}$ till $125^{\circ} \mathrm{C}$ and a final ramp of $8{ }^{\circ} \mathrm{C} / \mathrm{min}$ with a final temperature of $270^{\circ} \mathrm{C}$. The ion source temperature and MS transfer line temperature were set to $280{ }^{\circ} \mathrm{C}$ ajd $275^{\circ} \mathrm{C}$, and mass spectra were recorded in centroid mode using a mass acquisition range of 33-550 amu, a scan rate of 5 scans/s and an electron impact ionization energy of $70 \mathrm{eV}$. The interface and ion source were kept at $275^{\circ} \mathrm{C}$ and $250^{\circ} \mathrm{C}$. A mix of linear n-alkanes (from C7 to C40, Supelco Co.) were injected into the GC-MS under identical conditions to serve as external retention index markers.

To analyse the GC-MS data, chromatograms were exported in netCDF format and overlapping peaks were deconvoluted using AMDIS version 2.71 (Stein, 1999). The obtained spectra were then manually identified using the NIST MS Search v2.0 g software, using the NIST2011, FFNSC and Adams (Adams, 2007) target libraries, taking into account the expected retention time (retention indices), include in these same libraries. This resulted in the tentative identification of 228 target compounds (cf. Table S1 in supplemental material). Subsequently, these target compounds were integrated using a custom R script ( $\mathrm{R}$ Core Team, 2017) (available from the authors on request), which comprised three main steps: (1) preprocessing to denoise the chromatograms and (2) subtract background signal and (3) determining and integrating the target compound elution profiles using nonnegative least squares analysis. During the preprocessing step, the individual mass traces were denoised using a running median filtering followed by Savitsky-Golay filtering (window size of $4.3 \mathrm{~s}$ ). Subsequently, the signal of a blank chromatogram was subtracted from every chromatogram using a smoothed running quantile subtraction (quantile tau $=0.2$; window size of $5.1 \mathrm{~min}$ ). To extract and integrate the compound elution profiles, we used a file with all our target compounds containing the expected retention times and spectrum profiles of all our 228 target compounds (Table S1). We then extracted the elution profile for every compound in every chromatogram over a time restricted window using weighted nonnegative least square analysis (Lawson and Hanson, 1995). This was done by regressing each time scan in the chromatogram against each of the target compound spectra plus the spectra of other target compounds that were overlapping with the focal compound under analysis, and by using the mass weights described by (Stein and Scott, 1994) to give more weight to more informative mass traces. Next, the area under the curve (AUC) was computed from the estimated elution profiles using the trapezoidal rule. Finally, the obtained elution traces were manually inspected and only the compounds were retained that produced nice unimodal profiles across all samples. This resulted in a data file with reliable peak areas for 151 compounds (Table S2). To visually display the obtained data, we produced a heatmap using the pheatmap $R$ package, in which rows and columns were clustered using UPGMA hierarchical cluster and one minus the Pearson correlation was used as a 
distance metric and row $\mathrm{z}$ scores were used to give equal weight to all compounds (Fig. S1). A separate heatmap was also produced in which we also clustered the observed efficacy (proportionate reduction in D. suzukii infestation levels compared to the control calculated from the fitted Poisson generalized linear mixed-effects model (§2.5) together with the chemical data to determine possible compound candidates that might explain the observed repellency (Fig. S2).

\subsection{Statistical analysis}

Statistical analysis of the experiments was done using $\mathrm{R}$ version 3.4.2. Poisson GLMM's were constructed for the greenhouse and field trials using the glmer function of the lme4 package.

For the greenhouse test, the 'day of experiment' and 'cage repetition' were fitted as random effects and 'treatment' and 'bait type' as fixed effects without interaction. For the field efficacy trial (1), both 'plot row' and 'observation-' block level effects were fitted as random. 'log(fruit sample size)' was fitted as a fixed effect and 'treatment' and 'time after trial start' were fitted as fixed effects with interaction. In the commercial field efficacy trials (2), (3), (4), both 'larvae in fruit samples' and 'number of $D$. suzukii collected from the traps' were modelled, compensating for 'observation block level-', 'plot number-', 'fruit species-' and 'test site' random effects. 'Treatment' and 'observation time' were fitted as fixed effects with interaction. All models used random intercepts and Nelder-Mead optimization.

Contrast tests were performed using the emmeans package according to Dunnett, comparing to the untreated control at each observation timing to compensate for natural population development.

\section{Results}

\subsection{Greenhouse trials}

In greenhouse cage tests, no significant difference in attractiveness could be observed between the two baits used (grape or attractant medium) (ratio: 1.278 , SE: $0.280, P=0.2607$ ). No mortality occurred beyond the normal rate in the colony. Various efficacy levels of the Humulus lupulus products were observed (Fig. 1), with a significant reduction in infestation caused by HOPOO compared to the control (ratio: 0.392, SE: $0.095, \mathrm{P}=0.0011$ ). The treatments of both HOP07 (ratio: 0.541, SE: 0.130, P=0.0809) and HOP03 (ratio: 0.562, SE: $0.123, \mathrm{P}=0.0650$ ) showed a moderate reduction in oviposition when compared to the untreated control. Both the positive control samples 1octen-3-ol (ratio: 0.011, SE: 0.006, P 0.0001) and thymol (ratio: 0.294, $\mathrm{SE}: 0.081, \mathrm{P}=0.0001$ ) were confirmed to reduce oviposition.

\subsection{Field efficacy trials}

While pest pressure was high and uniform at the start of the trial (1), (late summer 2016), it declined towards the later observation times (est: -0.039, SE: $0.014, P=0.0049$ ). No significant reduction in oviposition could be detected at any one timepoint for the hop treated plots compared to the untreated control (est: 0.011, SE: 0.020, P =0.5757), nor did the positive controls 1-octen-3-ol (est: -0.036, SE: 0.029, $\mathrm{P}=0.2166$ ) and thymol (est: -0.036 , SE: $0.014, \mathrm{P}=0.0101$, increase) show a reduction across time when applied via dispensers. A slight significant reduction of infestation could be observed for thymol spray applications at the 4 week (est: -1.059 , SE: $0.290, P=0.0031$ ) and 5 week mark (est: $-1.351, \mathrm{SE}: 0.315, \mathrm{P}=0.0004$ ) when compared to the untreated control (Fig. 2). The application of thymol in a foliar spray application did however cause phytotoxic effects to the raspberry crop, making them unsuitable for further practical tests in this formulation.

During the trials at commercial field sites (B) and (C), (2), (3) and (4) (summer 2017), the larval count in fruits showed large variability for both treated and untreated plots (est: 0.040, SE:0.156, P=0.7973) leading to inconclusive results. The variability of trapped insect counts

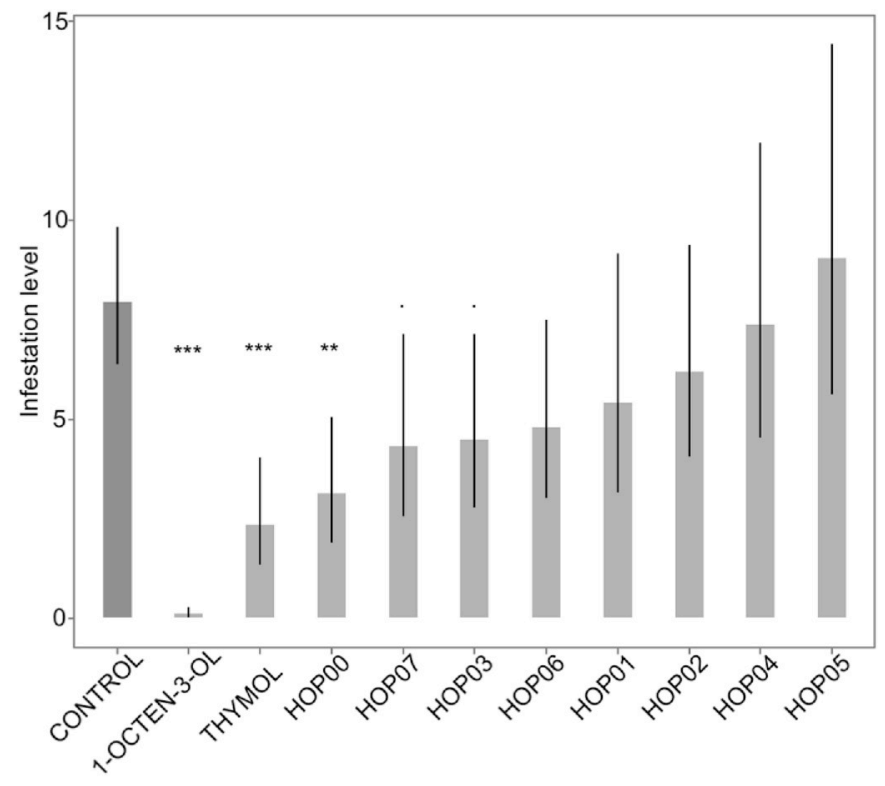

Fig. 1. Mean oviposition per greenhouse sample. Egg count $\pm 95 \%$ conf. interval (poisson), $24 \mathrm{~h}$ exposure, significance levels following Dunnett,

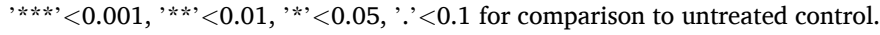

between treated plots was equally pronounced (est: -0.017 , SE: 0.087 , $\mathrm{P}=0,8450$ ). In general, no significant reduction of fruit infestation or population density could be observed in the treated plots compared to the untreated.

\subsection{Hop volatile composition}

When comparing the hop volatile composition of the different hop varieties (Fig. S1), no obvious link with alpha acid content was observed. The wild harvested HOP00 stood out from the brewing hops, showing a more extreme relative range of volatile concentrations. The two Halertau Hersbrucker samples (HOP02 and HOP03) were found to be clustered together, despite their different harvest year, whereas this clustering was less close for the Magnum samples (HOP06 and HOPOF), harvested in the same season (but from different producers). HOP00, which showed the highest efficacy level in the greenhouse trial was found to cluster together with HOPOF used in the field trials, supporting the choice of this batch for use in the field.

Studying the clustering of possible candidate compounds with efficacy (Fig. S2, box), we find that efficacy associates most closely with pseudolimonene, butyl acetate, 4-methylpentan-2-one, hexanal and alpha-terpinyl acetate.

\section{Discussion and conclusion}

During the greenhouse cage trials performed in 2016, an ovideterrent or repellent effect of certain hop varieties on $D$. suzukii could be shown in a controlled setting. HOP00 (Herbovan, K12300. wild harvest, $\mathrm{P}=0.0011$ ), HOP07 (var "CTZ", $\mathrm{P}=0.065$, moderate reduction) and HOP03 (var. "Halertau Hersbrucker", $P=0.0809$, moderate reduction) managed to reduce oviposition in short term, on a small scale test setup.

During commercial field trials, the application of hop pellets on the soil resulted in a pungent aroma throughout the crop that lasted for several weeks. The number of larvae and flies observed in fruits and traps showed no clear zonal pattern across the treated and untreated plots. Spatial distribution of volatiles remains an important element to be considered. Persistence and decay of the odorants, as well as habituation and adaptation of the flies to its components should not be underestimated. The short-term, close range effects of hop observed in the greenhouse trial might suggest that the active compound in hop is 


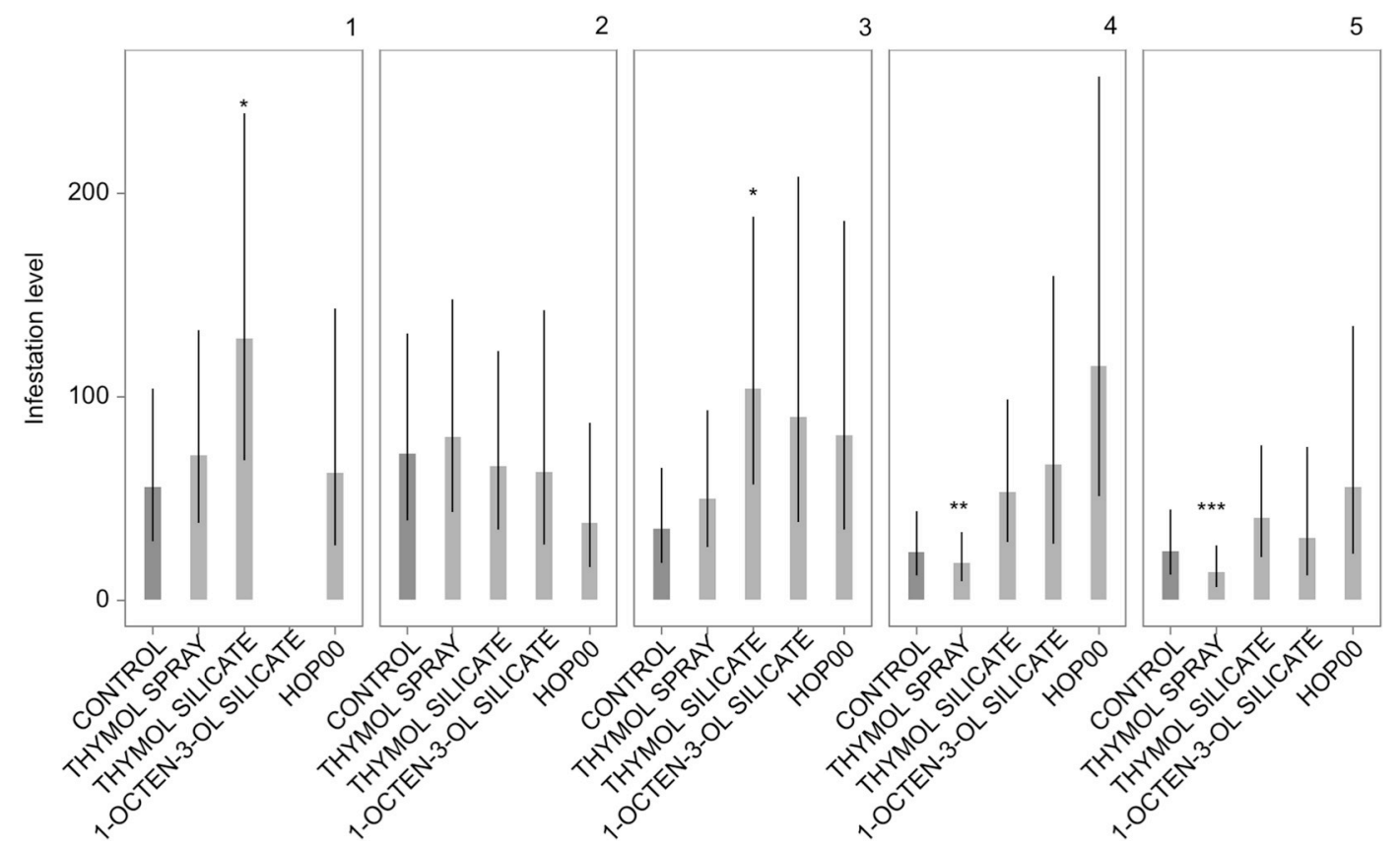

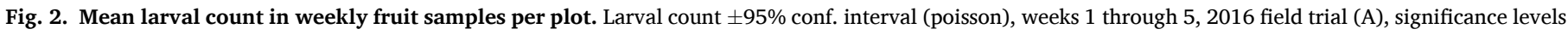

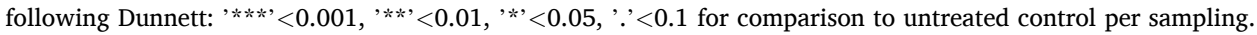

either short lived, is diluted by wind, does not spread sufficiently in the higher strata of the crop, or causes a simple adaptation/habituation of the flies in the field. In large scale practical trials, visual cues or other mechanisms might also play an important role in targeting behavior of D. suzukii (Rice et al., 2016).

A second element to consider is how monitoring traps deployed throughout a crop interact with repellent/deterrent strategies at the same location. Efficacy of push-pull systems on D. suzukii has recently been evaluated (Wallingford et al., 2018) and questions have been raised on the efficacy of a "pull" compound when combined with a "push" treatment. The observation of larvae in fruit is currently considered by us to be the only reliable indicator for infestation pressure. However, it necessitates a certain infestation level before detection is possible. In the current "zero-tolerance" market, we believe it is unlikely that a purely repellent based treatment could find a practical application in the absence of additional attractants. It is our opinion that further research on repellents of $D$. suzukii should include the effects of a monitoring system ("pull" component) to approximate commercial practice.

A multitude of plant essential oils have been studied in the past for their contact or volatile insecticidal effects on $D$. suzukii, in relatively confined, short term setups (Erland et al., 2015; Jang et al., 2016; Kim et al., 2016; Park et al., 2017, 2016). It has been shown that linalool, also found in some of our hop samples, activates olfactory receptor neurons similar to 1-octen-3-ol (de Bruyne et al., 2001).

Headspace SPME GC-MS is considered a reliable method for analyzing hop essential oils (Krofta and Nesvadba, 2005) capable of identifying a large number of compounds (Liu et al., 2018). Some of the volatiles we found to associate most strongly with greenhouse efficacy (Butyl acetate, Hexanal and (pseudo)-Limonene) have been described in the past as odour-active in D. suzukii (Abraham et al., 2015; Keller and Vosshall, 2007; Kleiber et al., 2014). While included in the target file, 1-octen-3-ol did not show up as relevant peak in any of the hop varieties.

To summarize, under controlled conditions, a repellent effect for D. suzukii could be demonstrated for the positive control 1-octen-3-ol and thymol and the test product HOP00. The transition from a smallscale experiment to commercial field trials proved to be challenging. Hop pellets are easily applicable from a practical point of view and can fit in a commercial setting with seasonal workers. The effects of attractants in trapping systems and the potential non-target effects should not be neglected. Pseudolimonene, Butyl acetate, 4-methylpentan-2-one hexanal and alpha-terpinyl acetate were found to associate with efficacy, and are suggested as potential targets for further study.

\section{Acknowledgements}

We would like to thank all participating growers for providing access to the field sites for the field phase of these experiments.

\section{Appendix A. Supplementary data}

\section{Funding}

This study was supported through KU Leuven's "Internal Funds": project code VAL/16/001 and "Internal Funds": project code C32/16/ 020(3E160416)) and a government fund for applied research "VLAIO LA-traject": project code 135079 (D. suzukii project).

The funders had no role in study design, data collection and analysis, decision to publish, or preparation of the manuscript.

\section{Declaration of interests}

None.

\section{References}

Abraham, J., Zhang, A., Angeli, S., Abubeker, S., Michel, C., Feng, Y., RodriguezSaona, C., 2015. Behavioral and antennal responses of Drosophila suzukii (Diptera: drosophilidae) to volatiles from fruit extracts. Environ. Entomol. 44, 356-367. http s://doi.org/10.1093/ee/nvv013.

Adams, R.P., 2007. Identification of essential oil components by gas chromatography/ mass spectroscopy, fourth ed. Allured Publishing Corporation, Carol Stream, IL.

Asplen, M.K., Anfora, G., Biondi, A., Choi, D.-S., Chu, D., Daane, K.M., Gibert, P., Gutierrez, A.P., Hoelmer, K.A., Hutchison, W.D., Isaacs, R., Jiang, Z.-L., Kárpáti, Z., Kimura, M.T., Pascual, M., Philips, C.R., Plantamp, C., Ponti, L., Vétek, G., Vogt, H., Walton, V.M., Yu, Y., Zappalà, L., Desneux, N., 2015. Invasion biology of Spotted 
wing Drosophila (Drosophila suzukii): a global perspective and future priorities. J. Pest. Sci. 88, 469-494. https://doi.org/10.1007/s10340-015-0681-Z.

Aydin, T., Bayrak, N., Baran, E., Cakir, A., 2017. Insecticidal effects of extracts of Humulus lupulus (hops) L. cones and its principal component, xanthohumol. Bull. Entomol. Res. 107, 543-549. https://doi.org/10.1017/S0007485317000256.

Basoalto, E., Hilton, R., Knight, A., 2013. Factors affecting the efficacy of a vinegar trap for Drosophila suzikii (Diptera; Drosophilidae). J. Appl. Entomol. 137, 561-570. http s://doi.org/10.1111/jen.12053.

Bedini, S., Flamini, G., Cosci, F., Ascrizzi, R., Benelli, G., Conti, B., 2016. Cannabis sativa and Humulus lupulus essential oils as novel control tools against the invasive mosquito Aedes albopictus and fresh water snail Physella acuta. Ind. Crops Prod. 85, 318-323. https://doi.org/10.1016/j.indcrop.2016.03.008.

Bedini, S., Flamini, G., Girardi, J., Cosci, F., Conti, B., 2015. Not just for beer: evaluation of spent hops (Humulus lupulus L.) as a source of eco-friendly repellents for insect pests of stored foods. J. Pest. Sci. 88, 583-592. https://doi.org/10.1007/s10340 -015-0647-1.

Cini, A., Anfora, G., Escudero-Colomar, L.A., Grassi, A., Santosuosso, U., Seljak, G., Papini, A., 2014. Tracking the invasion of the alien fruit pest Drosophila suzukii in Europe. J. Pest. Sci. 87, 559-566. https://doi.org/10.1007/s10340-014-0617-z.

Cini, A., Ioriatti, C., Anfora, G., 2012. A review of the invasion of Drosophila suzukii in Europe and a draft research agenda for integrated pest management. Bull. Insectol. $65,149-160$.

de Bruyne, M., Foster, K., Carlson, J.R., 2001. Odor coding in the Drosophila antenna. Neuron 30, 537-552. https://doi.org/10.1016/S0896-6273(01)00289-6.

De Keukeleire, J., Ooms, G., Heyerick, A., Roldan-Ruiz, I., Van Bockstaele, E., De Keukeleire, D., 2003. Formation and accumulation of $\alpha$-acids, $\beta$-acids, desmethylxanthohumol, and xanthohumol during flowering of hops ( Humulus lupulus L.). J. Agric. Food Chem. 51, 4436-4441. https://doi.org/10.1021/ jf034263z.

DeGrandi-Hoffman, G., Ahumada, F., Probasco, G., Schantz, L., 2012. The effects of beta acids from hops (Humulus lupulus) on mortality of Varroa destructor (Acari: varroidae). Exp. Appl. Acarol. 58, 407-421. https://doi.org/10.1007/s10493-0 12-9593-2.

Deletre, E., Schatz, B., Bourguet, D., Chandre, F., Williams, L., Ratnadass, A., Martin, T. 2016. Prospects for repellent in pest control: current developments and future challenges. Chemoecology 26, 127-142. https://doi.org/10.1007/s00049-016-0 214-0.

Dreves, A.J., Cave, A.L.J., 2014. A detailed guide for testing fruit for the presence of spotted wing Drosophila (SWD) larvae. Oregon State Univ. Ext. Serv. EM 9096 1-9.

PP 1/281 (1) Drosophila suzukii. EPPO Bull. 43, 2013, 386-388. https://doi.org/ 10.1111/epp.12055.

Erland, L.A.E., Rheault, M.R., Mahmoud, S.S., 2015. Insecticidal and oviposition deterrent effects of essential oils and their constituents against the invasive pest Drosophila suzukii (Matsumura) (Diptera: drosophilidae). Crop Protect. 78, 20-26. https://doi.org/10.1016/j.cropro.2015.08.013.

Eyres, G.T., Marriott, P.J., Dufour, J.-P., 2007. Comparison of odor-active compounds in the spicy fraction of hop ( Humulus lupulus L.) essential oil from four differen varieties §. J. Agric. Food Chem. 55, 6252-6261. https://doi.org/10.1021/ jf070739t.

Foster and, S.P., Harris, M.O., 1997. Behavioral manipulation methods for insect pestmanagement. Annu. Rev. Entomol. 42, 123-146. https://doi.org/10.1146/annurev. ento.42.1.123.

Gerber, N.N., lechevalier, H.A., 1967. Geosmin, an earthy-smelling substance isolated from actinomycetes. Biotechnol. Bioeng. 9, 321-327. https://doi.org/10.1002/bit. 260090305.

Grassi, A., Anfora, G., Maistri, S., Maddalena, G., De Gristofaro, A., Savini, G., Ioriatti, C., 2014. Development and efficacy of Droskidrink, a food bait for trapping Drosophila suzukii. In: IOBC VIII Workshop on Integrated Soft Fruit Production, pp. 26-28.

Hamilton, D., Ambrus, Á., Dieterle, R., Felsot, A., Harris, C., Petersen, B., Racke, K., Wong, S.S., Gonzalez, R., Tanaka, K., Earl, M., Roberts, G., Bhula, R., 2004. Pesticide residues in food-acute dietary exposure. Pest Manag. Sci. 60, 311-339. https://doi. org/10.1002/ps.865.

Haye, T., Girod, P., Cuthbertson, A.G.S., Wang, X.G., Daane, K.M., Hoelmer, K.A., Baroffio, C., Zhang, J.P., Desneux, N., 2016. Current SWD IPM tactics and their practical implementation in fruit crops across different regions around the world. J. Pest. Sci. 89, 643-651. https://doi.org/10.1007/s10340-016-0737-8.

Isman, M.B., 2006. Botanical insecticides, deterrents, and repellents in modern agriculture and an increasingly regulated world. Annu. Rev. Entomol. 51, 45-66. https://doi.org/10.1146/annurev.ento.51.110104.151146.

Jang, M., Kim, J., Yoon, K.A., Lee, S.H., Park, C.G., 2016. Biological activity of Myrtacea plant essential oils and their major components against Drosophila suzukii (Diptera: drosophilidae). Pest Manag. Sci. 73, 404-409. https://doi.org/10.1002/ps.4430.

Jones, G., Campbell, C.A.M., Hardie, J., Pickett, J.A., Pye, B.J., Wadhams, L.J., 2003. Integrated management of two-spotted spider mite Tetranychus urticae on hops using hop B-acids as an antifeedant together with the predatory mite Phytoseiulus persimilis. Biocontrol Sci. Technol. 13, 241-252. https://doi.org/10.1080/0958315021 000073501

Jones, G., Campbell, C.A.M., Pye, B.J., Maniar, S.P., Mudd, A., 1996. Repellent and Oviposition-Deterring Effects of Hop Beta-Acids on the Two-Spotted Spider Mite Tetranychus Urticae. Pestic. Sci, vol. 47, pp. 165-169. https://doi.org/10.1002/(SICI) 1096-9063(199606)47:2<165::AID-PS392>3.0.CO;2-R.

Katsiotis, S.T., Langezaal, C.R., Scheffer, J.J.C., 1990. Composition of the essential oils from leaves of various Humulus lupulus L. cultivars. Flavour Fragrance J. 5, 97-100. https://doi.org/10.1002/ffj.2730050208.
Keller, A., Vosshall, L.B., 2007. Influence of odorant receptor repertoire on odor perception in humans and fruit flies. Proc. Natl. Acad. Sci. Unit. States Am. 104, 5614-5619. https://doi.org/10.1073/pnas.0605321104.

Kim, J., Jang, M., Shin, E., Kim, J., Lee, S.H., Park, C.G., 2016. Fumigant and contact toxicity of 22 wooden essential oils and their major components against Drosophila suzukii (Diptera: drosophilidae). Pestic. Biochem. Physiol. 133, 35-43. https://doi. org/10.1016/j.pestbp.2016.03.007.

Kleiber, J.R., Unelius, C.R., Lee, J.C., Suckling, D.M., Qian, M.C., Bruck, D.J., 2014 Attractiveness of fermentation and related products to spotted wing Drosophila (Diptera: drosophilidae). Environ. Entomol. 43, 439-447. https://doi.org/10.160 3/EN13224.

Knaden, M., Strutz, A., Ahsan, J., Sachse, S., Hansson, B.S., 2012. Spatial representation of odorant valence in an insect brain. Cell Rep. 1, 392-399. https://doi.org/10.10 16/j.celrep.2012.03.002.

Kovacevic, M., Kac, M., 2001. Solid-phase microextraction of hop volatiles q Potential use for determination and verification of hop varieties. J. Chromatogr., A 918, $159-167$.

Krofta, K., Nesvadba, V., 2005. Utilisation of solid-phase microextraction in hop oils analyses. Acta Hortic. (Wagening.) 668, 191-200. https://doi.org/10.17660/Act aHortic.2005.668.24.

Lawson, C.L., Hanson, R.J., 1995. Solving Least Squares Problems, vol. 15. Siam.

Liu, Z., Wang, L., Liu, Y., 2018. Rapid differentiation of Chinese hop varieties (Humulus lupulus) using volatile fingerprinting by HS-SPME-GC-MS combined with multivariate statistical analysis. J. Sci. Food Agric. 98, 3758-3766. https://doi.org/ $10.1002 /$ jsfa.8889.

Meilgaard, M.C., Reid, D.S., Wyborski, K.A., 1982. Reference standards for beer flavor terminology system. J. Am. Soc. Brew. Chem. 40, 119-128.

Nance, M.R., Setzer, W.N., 2011. Volatile components of aroma hops (Humulus lupulus L.) commonly used in beer brewing. J. Brew. Distill. 2, 16-22.

Nur, A., Englund, J.-E., Åhman, I., Lieberg, M., Johansson, E., 2011. Perception of pesticide use by farmers and neighbors in two periurban areas. Sci. Total Environ. 412-413, 77-86. https://doi.org/10.1016/j.scitotenv.2011.10.022.

Park, C., Jang, M., Shin, E., Kim, J., 2017. Myrtaceae plant essential oils and their $\beta$-triketone components as insecticides against Drosophila suzukii. Molecules 22, 1050. https://doi.org/10.3390/molecules22071050.

Park, C.G., Jang, M., Yoon, K.A., Kim, J., 2016. Insecticidal and acetylcholinesterase inhibitory activities of Lamiaceae plant essential oils and their major components against Drosophila suzukii (Diptera: drosophilidae). Ind. Crops Prod. 89, 507-513. https://doi.org/10.1016/j.indcrop.2016.06.008.

R Core Team, 2017. R: A Language and Environment for Statistical Computing. R Foundation for Statistical Computing, Vienna, Austria.

Rapior, S., Marion, C., Pélissier, Y., Bessière, J.-M., 1997. Volatile composition of fourteen species of fresh wild mushrooms ( boletales ). J. Essent. Oil Res. 9, 231-234. https://doi.org/10.1080/10412905.1997.9699468.

Renkema, J.M., Buitenhuis, R., Hallett, R.H., 2017. Reduced Drosophila suzukii infestation in berries using deterrent compounds and laminate polymer flakes. Insects 8, 117. https://doi.org/10.3390/insects8040117.

Renkema, J.M., Wright, D., Buitenhuis, R., Hallett, R.H., 2016. Plant essential oils and potassium metabisulfite as repellents for Drosophila suzukii (Diptera: drosophilidae). Sci. Rep. 6, 21432. https://doi.org/10.1038/srep21432.

Rice, K.B., Short, B.D., Jones, S.K., Leskey, T.C., 2016. Behavioral responses of Drosophila suzukii (Diptera: drosophilidae) to visual stimuli under laboratory, semifield, and field conditions. Environ. Entomol. 45, 1480-1488. https://doi.org/10.1093/ee/ nvw123.

Smirle, M.J., Zurowski, C.L., Ayyanath, M.-M., Scott, I.M., MacKenzie, K.E., 2017. Laboratory studies of insecticide efficacy and resistance in Drosophila suzukii (Matsumura) (Diptera: drosophilidae) populations from British Columbia, Canada. Pest Manag. Sci. 73, 130-137. https://doi.org/10.1002/ps.4310.

Stein, S.E., 1999. An integrated method for spectrum extraction and compound identification from gas chromatography/mass spectrometry data. J. Am. Soc. Mass Spectrom. 10, 770-781.

Stein, S.E., Scott, D.R., 1994. Optimization and testing of mass spectral library search algorithms for compound identification. J. Am. Soc. Mass Spectrom. 5, 859-866.

Stensmyr, M.C., Dweck, H.K.M., Farhan, A., Ibba, I., Strutz, A., Mukunda, L., Linz, J., Grabe, V., Steck, K., Lavista-Llanos, S., Wicher, D., Sachse, S., Knaden, M., Becher, P. G., Seki, Y., Hansson, B.S., 2012. A conserved dedicated olfactory circuit for detecting harmful microbes in Drosophila. Cell 151, 1345-1357. https://doi.org/10 .1016/j.cell.2012.09.046.

Verzele, M., 1986. 100 years of hop chemistry and its relevance to brewing. J. Inst. Brew. $92,32-48$.

Wallingford, A.K., Cha, D.H., Linn, C.E., Wolfin, M.S., Loeb, G.M., 2017. Robust manipulations of pest insect behavior using repellents and practical application for integrated pest management. Environ. Entomol. 46, 1041-1050. https://doi.org/ 10.1093/ee/nvx125.

Wallingford, A.K., Cha, D.H., Loeb, G.M., 2018. Evaluating a push-pull strategy for management of Drosophila suzukii Matsumura in red raspberry. Pest Manag. Sci. 74, 120-125. https://doi.org/10.1002/ps.4666.

Wallingford, A.K., Connelly, H.L., Brind'Amour, G.D., Boucher, M.T., Mafra-Neto, A., Loeb, G.M., Dore Brind'Amour, G., Boucher, M.T., Mafra-Neto, A., Loeb, G.M., 2016. Field evaluation of an oviposition deterrent for management of spotted-wing Drosophila, Drosophila suzukii, and potential nontarget effects. J. Econ. Entomol. 109, 1779-1784. https://doi.org/10.1093/jee/tow116.

Wallingford, A.K., Hesler, S.P., Cha, D.H., Loeb, G.M., 2015. Behavioral response of spotted-wing Drosophila, Drosophila suzukii Matsumura, to aversive odors and a potential oviposition deterrent in the field. Pest Manag. Sci. 72, 701-706. htt ps://doi.org/10.1002/ps.4040. 